\title{
Que farei com estes clássicos?
}

\section{Silvina Pereira}

Alexandra Ferreira,

fot. Pedro Soares.
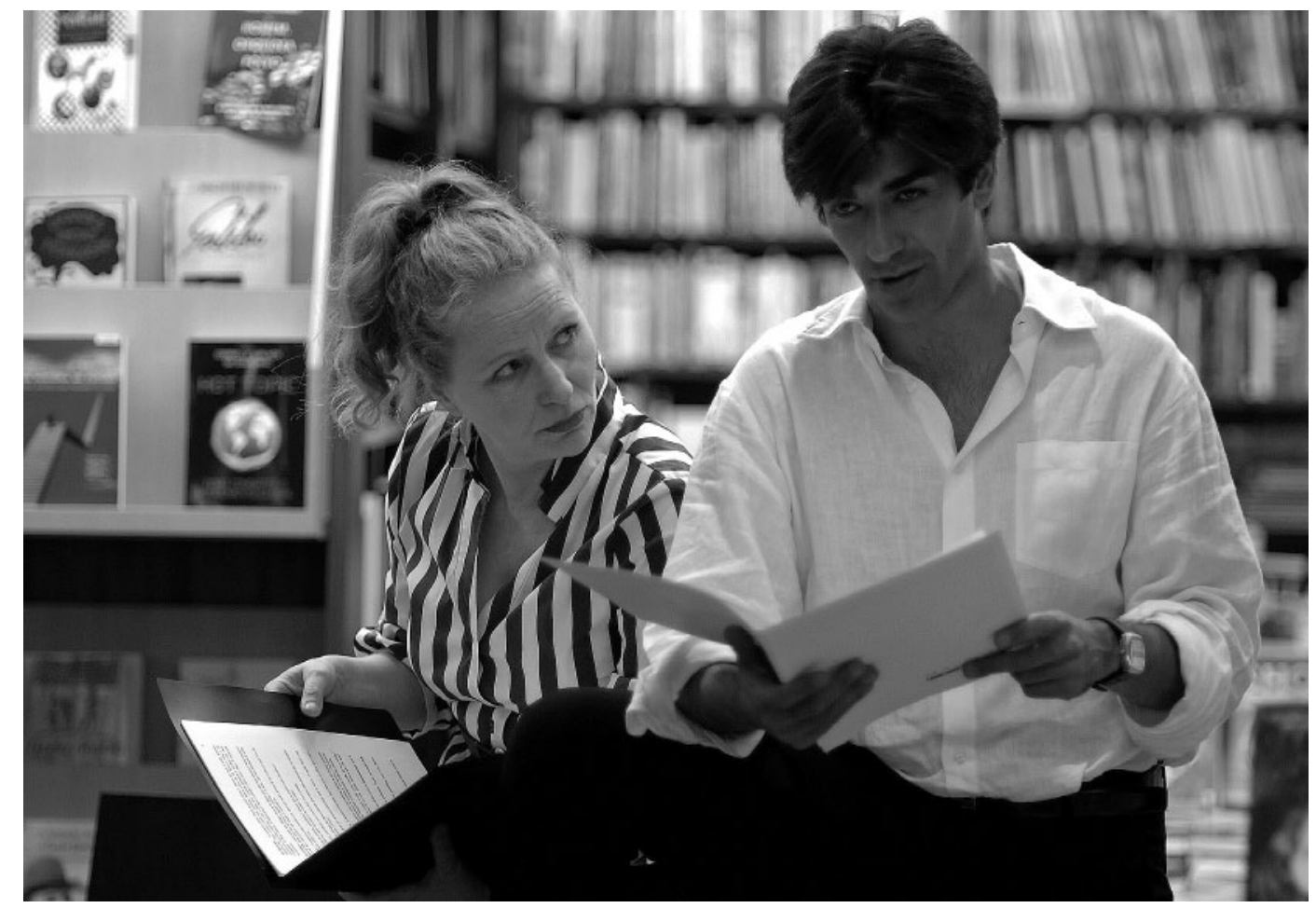

Silvina Pereira é actriz, encenadora $\mathrm{e}$ dramaturgista. Fundou e é directora artística do Grupo de Teatro Maizum. Doutorada em Estudos de Teatro pela Faculdade de Letras da Universidade de Lisboa com a tese Tras a nevoa vem o sol: As comédias de Jorge Ferreira de Vasconcelos, integra actualmente como investigadora o Centro de Estudos Clássicos da

mesma Faculdade, onde desenvolve, com uma bolsa de pósdoutoramento da FCT, uma reflexão teórica sobre a componente prática de Encenar o teatro clássico, hoje.
No meu percurso como actriz e encenadora, trabalhei com vários encenadores, com diferentes perspectivas estéticas e ideológicas e, de uma forma quase exclusiva, com textos de autores vivos, ou que pretendiam ter algo a dizer à cultura e à sociedade do último quartel do século $X X$.

Foi a partir destas experiências artisticas e teatrais que me fui apercebendo de que, para ver activamente o teatro contemporâneo e compreender melhor a dramaturgia actual, é conveniente e mais enriquecedor conhecer os clássicos. Não por razões de arqueologia literária, ou por querer representar algo que nunca ninguém fez antes, mas porque estes textos transportam e contêm histórias e emoções da natureza humana em estado puro e são fonte de vitalidade, de um pulsar de razão e de emoção, que nos deixa ver e compreender melhor o nosso presente. Claro que as condições de recepção são hoje diferentes. Por isso, há necessidade de um trabalho dramatúrgico que ponha em evidência, ao nosso olhar, as linhas de força, os ritmos, as pulsões e as sensibilidades que atravessam a acção e as personagens dessas obras.

Percebi também, através do contacto com esses textos, que a experiência cénica é fundamental para o conhecimento de uma obra dramática. Porque a teatralidade é um atributo específico do teatro, e a passagem pelo crivo da prática cénica possibilita testar e potenciar teatralmente as componentes visuais e sonoras de um texto, como acontece com Shakespeare, Calderón ou Molière. 0 jogo dramático, a circulação da palavra através do desdobramento personagem/actor - e a qualidade de representação de um texto clássico reflectemse, segundo Adamov, na sua capacidade de "projecção no mundo sensivel dos estados e das imagens que constituem as forças escondidas (...) a manifestação do conteúdo escondido, latente, que alberga os princípios do drama" (Adamov apud Pavis 2002: 359)

Até há relativamente pouco tempo, o conhecimento do teatro clássico português não passava de umas quantas obras de três ou quatro autores, sendo o mais conhecido Gil Vicente. Mas mesmo dele, e de algumas das suas obras, por não terem sido com mais frequência representadas, pôde dizer António José Saraiva que a "demonstração mais cabal da incapacidade dramática de Gil Vicente parece-me estar no seu teatro romanesco" onde "se não encontram nem a situação nem o carácter" (Saraiva 1981:101). Um criador, que tenha trabalhado em palco o teatro vicentino, poderá, sem dúvida, subscrever a opinião de Luis Miguel Cintra que já considerou a obra 


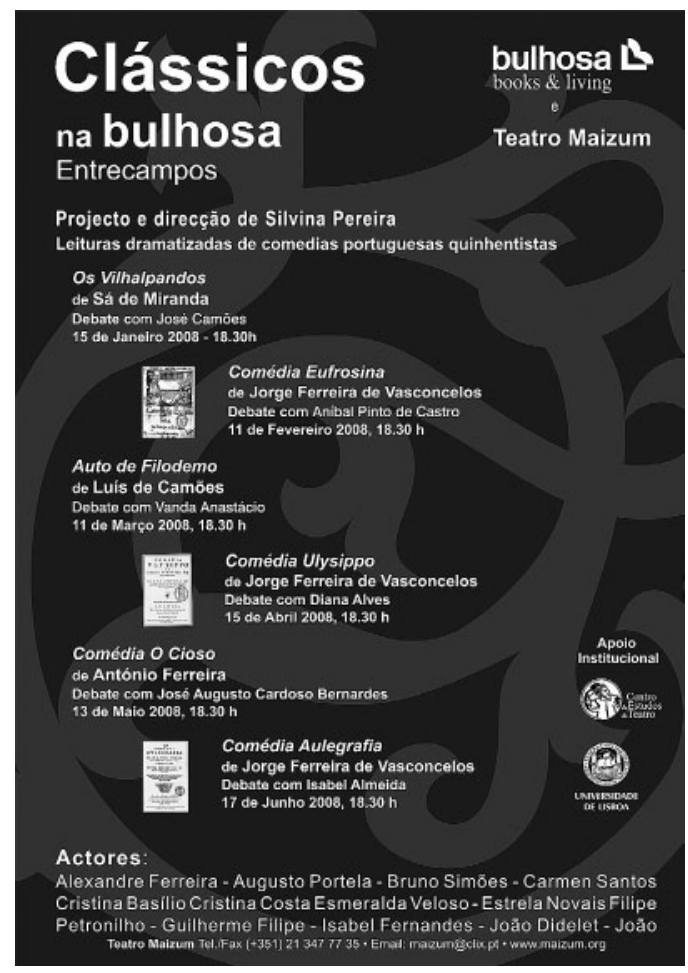

de Gil Vicente como sendo "da mais alta poesia cénica, muito estimulante para um encenador moderno". ${ }^{1}$ Bem gostariamos que António José Saraiva tivesse assistido à Tragicomedia de Don Duardos de Gil Vicente, em 2006, pela companhia de teatro Nao D'Amores, encenado por Ana Zamora, e ouvido os actores falarem da sua experiência como intérpretes. Teria assim repensado, certamente, a sua reflexão sobre o teatro de Gil Vicente.

A representação de Dom Duardos no espaço para o qual foi concebido - os Claustros de los Dominicos, em Almagro - naquela noite em que o ouvi, naquele sítio em que o vi, carregado de tão real simbolismo por se tratar, ademais, de um verdadeiro espaço renascentista, tornou bem claro que um espectáculo teatral vicentino é bem mais do que o texto escrito por Gil Vicente. Naquela quente noite de verão, naquele claustro, debaixo do céu estrelado, viveu-se uma experiência total de palavra/corpo, pelo que os actores, falando no dia seguinte sobre 0 processo de trabalho, evidenciaram a forte e particular experiência vivida e o percurso espiritual/poético que a representação do texto Ihes permitiu.

São experiências emocionais e estéticas desta natureza, conhecidas e vividas pelos actores e pelos que participam na criação de um espectáculo, e reconhecidas e partilhadas
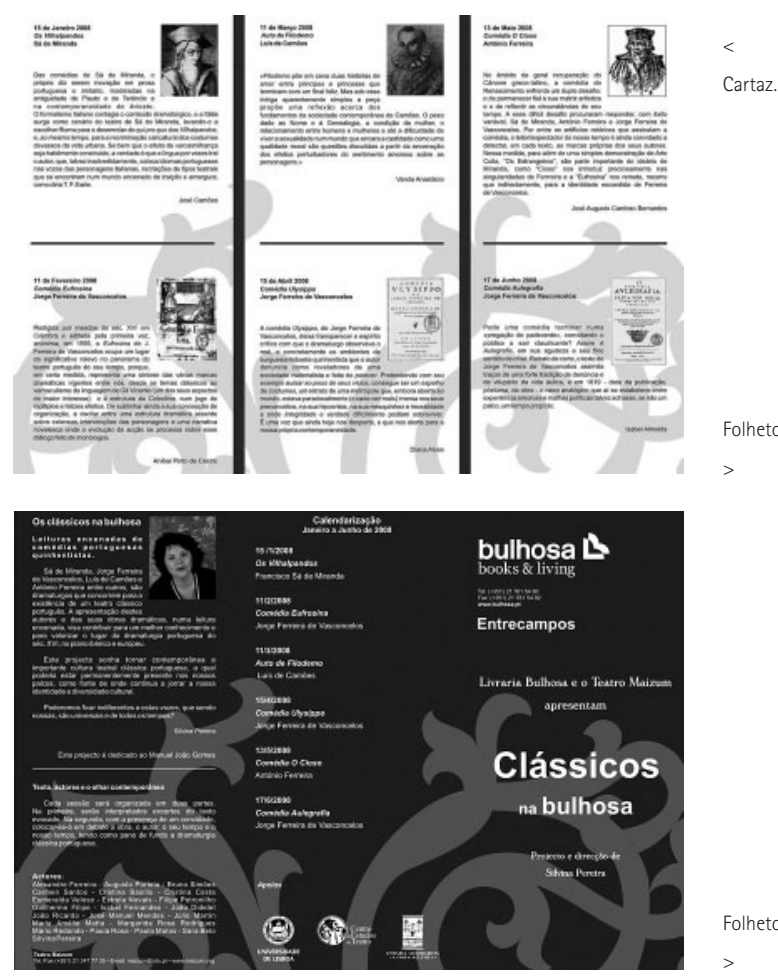

$>$

pelo público, que convidam a uma reflexão centrada na experiência da "representação" e não uma análise exclusivamente logocêntrica. 0 texto dramático, depois de limpo do pó das estantes, não se revela plenamente na mudez e na solidão da leitura. Ele transmite-nos a consciência do facto "que o texto do drama dirige-se intencionalmente para uma experiência colectiva de uma acção posta em presença" (Kelera 1986: 23).

Uma boa forma de reconhecer a teatralidade de uma obra, na ausência de condições de produção para a pôr em cena, é através de uma récita ou de uma leitura encenada, onde estão patentes as relações dialécticas entre a escrita e a oralidade, entre o texto dramático e a sua realização vocal: "Esta é a razão pela qual a leitura teatralizada do drama se revela muito útil. Ela permite interpretar o teatro a partir de modelos de actos cénico e, ao mesmo tempo, interpretar o teatro a partir de estruturas literárias do drama" (Ratajczak 1986: 48).

\section{Os clássicos na Bulhosa}

0 programa de leituras encenadas que organizei na Livraria Bulhosa, de Janeiro a Junho de 2008, teve o propósito, conforme se podia ler no folheto de apresentação, de "mostrar a riqueza da cultura teatral clássica portuguesa,
No suplemento "Destaque", 7 de Junho de 2002. 
Silvina Pereira fot. Pedro Soares.

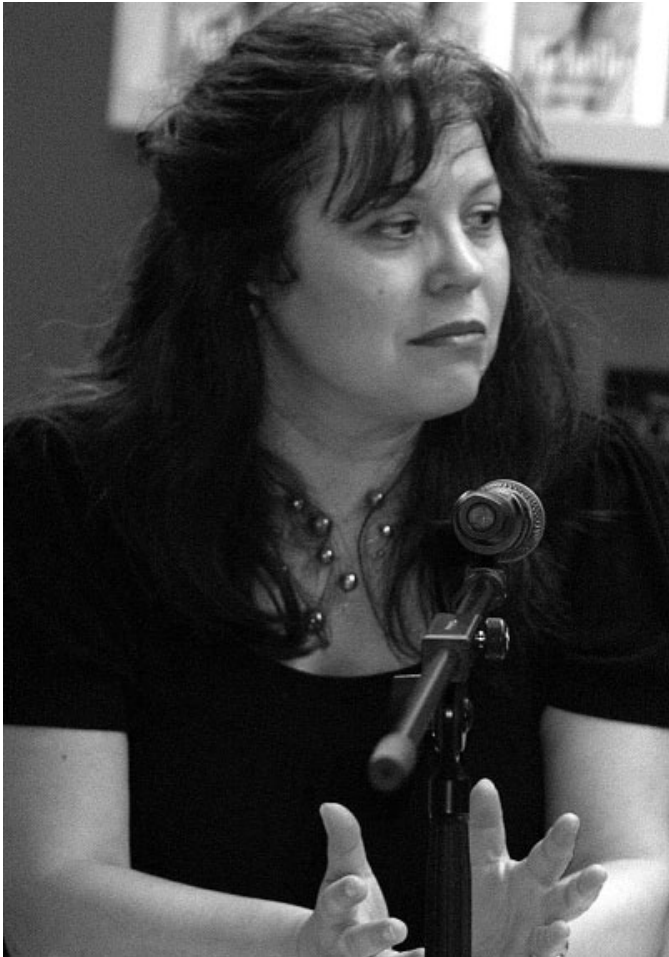

havia sequer edições no mercado. A proposta foi aceite pela sua qualidade e originalidade mas também porque, a título pessoal, não deixava de me intrigar que num país como a Espanha - comparável pela proximidade e ainda pela similitude/partilha da produção dramatúrgica dessa época - se continuem a representar com sucesso e por todo o pais os ditos Clássicos, e em Portugal eles sejam tão raramente vistos e ouvidos em palco, porque tidos por dificeis, desinteressantes ou mesmo irrepresentáveis (causa ou consequência do seu desaparecimento dos curricula escolares?). (...)

Moral da história: como os próprios apresentadores notaram alguns até pronunciando um 'mea culpa', caiu ali por terra o mito da não representabilidade desses textos, e essa não terá sido a menor das virtudes dos "Clássicos na Bulhosa".

Para além do mito da "irrepresentabilidade", deve acrescentar-se que a tradição crítica deste repertório enferma da atribuição de um excessivo peso da análise textual em detrimento de uma efectiva análise dramatúrgica. A visão literária, cuja tendência é focar sobretudo aspectos como a análise crítica do texto, 0 tema, a filiação ao género, ou o lugar no canône, faz esquecer que a leitura de uma comédia exige do leitor a posse de uma consciência metodológica que reconheça os signos teatrais e os visualize através da imaginação, dado o "duplo estatuto da obra dramática: obra cristalizada tradicionalmente nas categorias literárias e obra destinada à realização teatral" (Ratajczak 1986: 41).

\section{"segura quem pode: sabe quem alcança"}

Quintiliano dizia ter "mais prazer a ouvir versos do que a lê-los" (Kowzan 1988:363), afirmação que, mais do que revelar um gosto pessoal, mostra o impacto da palavra dita. Mas, ser leitor ou espectador de qualquer das obras acima referidas, acarreta nos nossos dias algumas dificuldades. Uma delas é assinalada por José Augusto Cardoso Bernardes:
André Dourado Agradeço

ao autor a generos
A proposta da Silvina Pereira de centrar este programa nos Clássicos, dedicando os seus primeiros meses aos autores quinhentistas, foi para nós um contra-desafio, tanto mais que, de muitos deles, não 


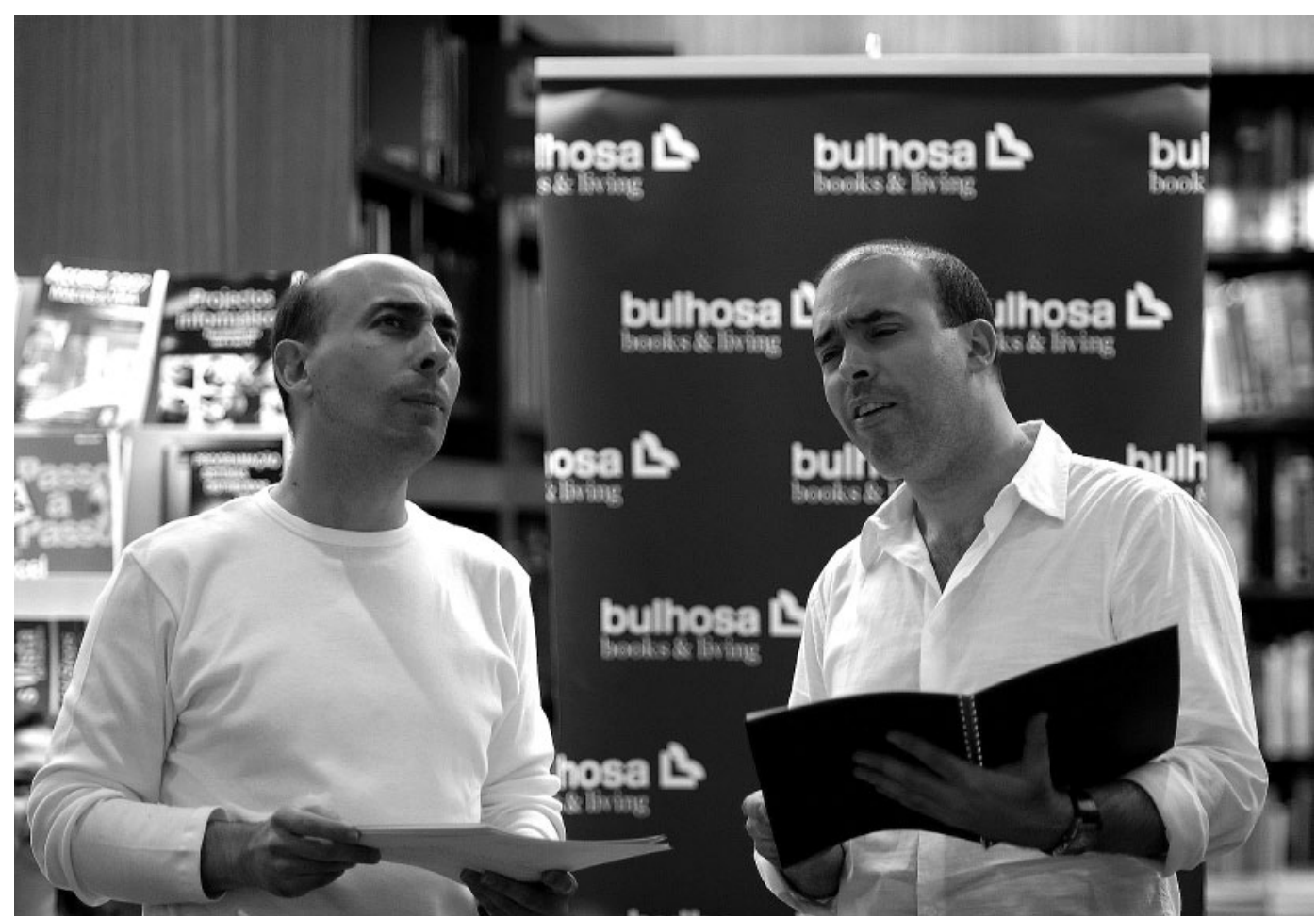

Centrada na palavra, quando a palavra era, ela própria, a causa e a consequência da acção e a sede do Logos, a comédia do Renascimento coloca hoje problemas de representação acrescidos, exactamente porque, no nosso tempo, a palavra se encontra deperecida e desqualificada. Representar as comédias de António Ferreira (como as de Sá de Miranda ou Jorge Ferreira de Vasconcelos) pressupõe, por isso, um processo de reabilitação do acto de dizer. Na sua singularidade formal e semântica, cada palavra transforma-se em objecto de pensamento dilatado. É isso que faz deste tipo de teatro um acontecimento estranho e ao mesmo tempo produtivo. "Estranho" porque contradiz a pressa instrumental com que hoje falamos; produtivo porque nos prova que nem sempre foi assim e que não tem que ser assim forçosamente.

Nesse sentido, para além do alcance patrimonial de que se reveste e dos efeitos de beleza que pode originar, a encenação cuidada de peças do século XVI pode ainda constituir um excelente antídoto contra um certo tipo de barbárie anti-humanista que caracteriza o nosso quotidiano.

0 texto acima transcrito oferece um trilho de reflexão, deveras profícuo. Algumas são as dificuldades na transmissão deste repertório e, seguramente 0 desconhecimento do valor e do poder da palavra é um deles. A "estranheza" é experimentada, logo à partida, pelos actores. Perceber e dizer esse discurso constitui uma empresa draconiana, um trabalho árduo que requer competências específicas. Ou seja, trabalhar hoje a encenação e interpretação dos clássicos implica todo um programa de reflexão em vários campos, que ajudem a conseguir com eficácia uma boa recepção do espectáculo.

Outra das dificuldades prende-se com o facto de esse teatro não despertar uma memória no espectador. 0 público contemporâneo, arredado dessas remotas paragens, não tem referências nem hábitos de "ver" e "ouvir" esses textos. Falta esse conhecimento, ou melhor, essa intima convivência com os nossos clássicos, que faria deles parentes próximos em vez de parentes remotos, e em muito atenuaria a impressão de dificuldade, fazendo emergir, em última instância, um imaginário teatral português que, infelizmente, não existe, porque não se vê representado.

Por isso, a começar pelos criadores e a acabar nos espectadores, a nossa condição, é a de estrangeiros, em casa própria. Vanda Anastácio, oferece-nos uma reflexão global, sobre esta malfadada "terra incógnita", onde, ainda assim, pode prevalecer a surpresa e o agrado:

0 ciclo de leituras encenadas proposto e realizado pelo Teatro Maizum na Livraria Bulhosa pode descrever-se como uma surpresa e uma revelação.

A surpresa esteve quase sempre da parte do público.

Estranhamente, são muitas as pessoas que estão convencidas de que a Cultura Portuguesa se reduz aos estreitos horizontes dos seus dirigentes contemporâneos..

0 sentimento de estar perante uma revelação parece ter sido comum a todos. Como o repertório teatral do nosso pais não é ensinado na escola, como as edições acessiveis são poucas e como raramente há a oportunidade de ouvir representar teatro português, poucos são aqueles que alguma vez leram essas peças ou as viram em palco e, mais raros ainda, aqueles que sabem quão actuais elas realmente são. Essas sessões permitiram dar a ver um património que é nosso, e provar ao público curioso, cada vez mais numeroso de sessão para sessão, que o teatro português do século dos Descobrimentos constitui uma memória cultural forte, capaz de "mexer connosco" ao fim de centenas de anos, capaz de fazer rir e de pôr o dedo em "feridas" sociais e culturais que nos incomodam ainda hoje e que parecem ser de sempre...

Foi uma oportunidade rara de poder apreciar e valorizar um património hoje muito esquecido, não porque seja escasso, ou porque não tenha interesse, mas sobretudo por falta de um orgulho nas coisas nacionais que vem sendo destruído ao longo de décadas de crises nacionais sucessivas. E não se interprete este apelo à valorização do teatro clássico português como uma visão primariamente nacionalista das coisas: na Europa multicultural que
Depoimento inédito gentilmente cedido por José Augusto Cardoso Bernardes. Agradeço ao autor a generosa disponibilização deste texto. 


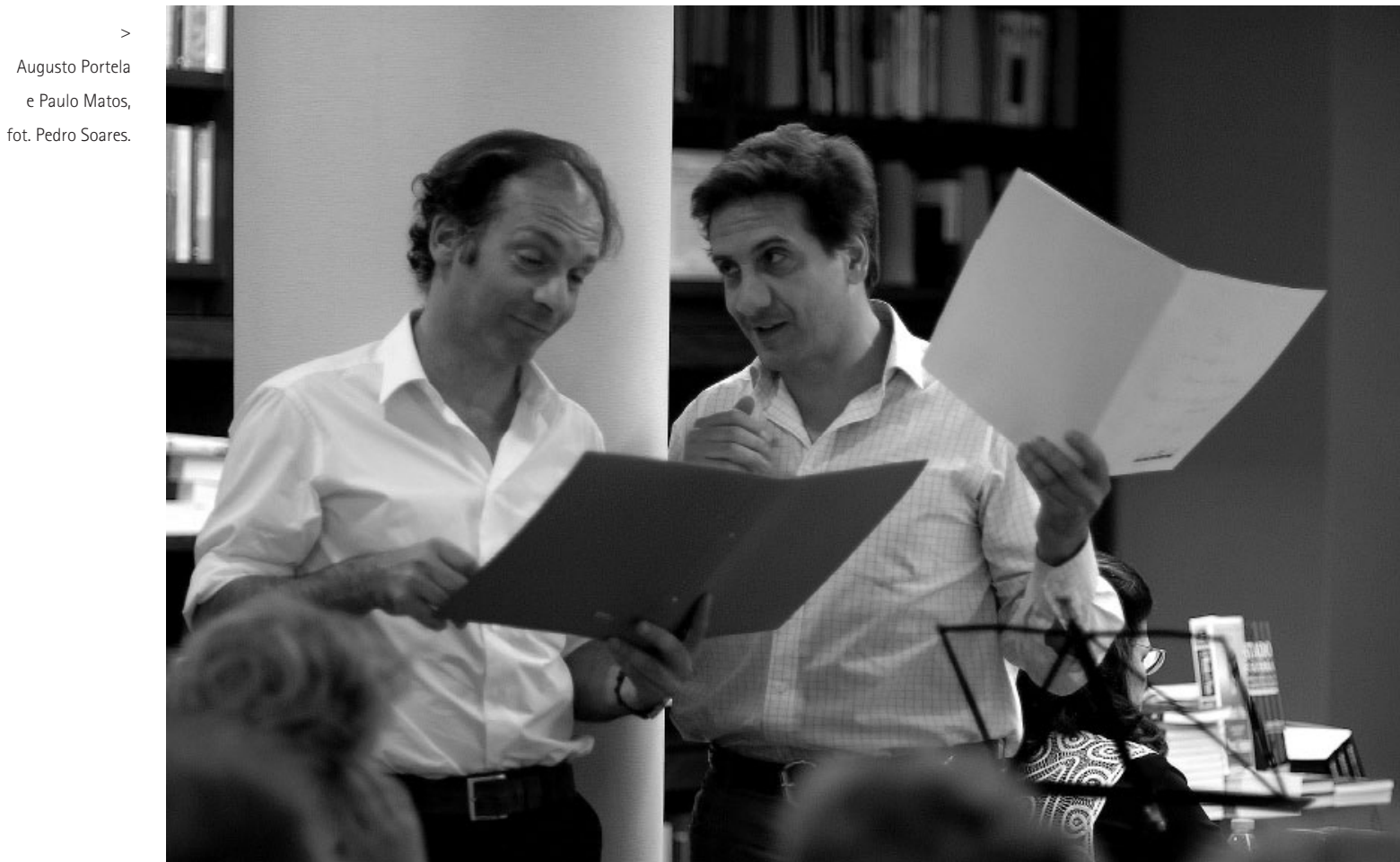

se anuncia, na qual todos os membros têm direito a um lugar, Portugal não pode, por ignorância, pelo apagamento da sua memória, por desprezo do que é seu e do que é capaz de dar, aparecer como um lugar vazio. ${ }^{4}$

0 conhecido conceito de "espaço vazio" proposto por Peter Brook, em tudo difere do "lugar vazio" evocado por Vanda Anastácio. 0 primeiro é um transfigurador e positivo lugar essencial, enquanto o segundo é a ausência que falta preencher, teatralmente significando o "Inverno do nosso descontentamento".

"Este feliz encontro dos nossos espíritos"

Quer os convidados, quer o público, constataram que este repertório dialoga com e interpela a nossa

contemporaneidade e que, ainda hoje, "ver" e "ouvir" estes textos proporciona um aliciante e estimulante prazer estético.

A propósito da Comedia Aulegrafia, tal como aconteceu com a Eufrosina e a Ulysippo, a experiência da leitura em voz alta revelou um potencial teatral que deixou mais uma vez surpreendidos os próprios actores, referindose às palavras de Jorge Ferreira de Vasconcelos como sendo "gostosas de dizer como o mel". A leitura pública na Livraria Bulhosa a 17 de Junho de 2008, como no ano seguinte, no Teatro Nacional, a 15 de Setembro de 2009 mostrou a presença e o despertar da voz de grandes personagens teatrais, à espera somente de que aquelas duas leituras encenadas, desse "magnífico teatro" como Ihe chamou Isabel Almeidas, se venham brevemente a transformar num feliz espectáculo.

Mudam-se os tempos, mudam-se as vontades e, por isso, dever-se-ão ultrapassar preconceitos, resgatando para o teatro o que é do teatro. No dia 27 de Março de 2010, a actriz Dame Judi Dench relembrou que "temos a responsabilidade de continuar essa tradição de divertimento, de educação e de edificação dos nossos públicos".
Representar o teatro clássico de Sá de Miranda, de Camões, de António Ferreira e as magníficas comédias de Jorge Ferreira de Vasconcelos e tanto outro teatro português é uma obrigação dos criadores portugueses e a missão de qualquer Teatro Nacional. Razões para isso não faltarão, sendo uma delas a da constituição de um repertório teatral clássico português capaz de dialogar e de se afirmar perante outros repertórios congéneres europeus, como o sonhou Almeida Garrett "andemos com a missão que é nobre e generosa" e, quanto ao mais, "se queremos que a peça seja percebida, então é preciso saber fazê-la cantar" (Brook 1977:59). 0 público, agradece $e$ aplaude.

\section{Referências bibliográficas}

PAVIS, Patrice (2002), Dictionnaire du théâtre, Paris, Armand Colin KELERA, Józef (1986), "La lecture du drame", Le texte dramatique/La lecture et la scène, Romanica Wratislaviensia, XXVI, Wroclaw, pp. 21-28.

SARAIVA, António José (1981), Gil Vicente e o fim do teatro medieval Lisboa, Livraria Bertrand.

KOWZAN, Tadeusz (1988), "Texte écrit et représentation théâtrale", Poétique,

75, pp. 363-372.

RATAJCZAK, Dobrochna (1986), "Lire - Voir - Savoir", Le texte dramatique/La lecture et la scène, Romanica Wratislaviensia, XXVI, Wroclaw, pp. 41-49.

BROOK, Peter (1977), L'Espace vide: Écrits sur le théâtre, Paris, Éditions du Seuil. 